\title{
An Insight Into the Promise and Problems of Combining Life History and Grounded Theory Research
}

\author{
Bronwyn Betts \\ Anglia Ruskin University, Cambridge, UK
}

\begin{abstract}
This paper describes the research carried out in partial fulfilment of the degree of doctor of education. The study was qualitative in nature with a phenomenological interpretive paradigm dominating the philosophical approach. The research methods adopted combined life story and grounded theory. As far as the author has been able to determine there are very few, if any studies which have applied this approach specifically to this area of research which investigated the influence life history has on attitude to lifelong learning. Twenty five respondents were interviewed in face-to-face informal interviews. The main aim was to elicit the respondent's subjective interpretation of the interaction between school, family, work, and learning within their lives. The researcher was then able to identify when they occurred and what or who made them particularly meaningful. This paper describes how initial decisions were made regarding the substantive area for the research. Sampling technique and method for collecting the data is discussed and a worked example is given of how the data was analysed. It is intended that this paper will give an insight into the challenge of combining these two much debated methods of research. The empirical data lead to some interesting findings which educators and policy makers will find helpful in order to strengthen the school, college, and workplace interface.
\end{abstract}

Keywords: life history, grounded theory, methodology, family, school, learning

\section{The Raison D'être of the Research}

At the inception of her doctoral studies the researcher was facilitating the reflective practice of a group of students studying for a postgraduate degree in human resource management. An early observation was made as a result of reading their reflective notes supported a perspective which pointed to the strong influence that experiences in the early years had on their current (positive) attitude to learning. Therefore, the initial motivation for the study was to seek further understanding of an otherwise little understood area, namely, the influence life history can have on attitude to learning in later life.

\section{The Theoretical and Methodological Framework}

The study was a qualitative study with a phenomenological interpretive paradigm dominating the philosophical approach adopted. The research methods were chosen because of their close association with this

Bronwyn Betts, Ph.D., Lord Ashcroft International Business School, Anglia Ruskin University.

Correspondence concerning this article should be addressed to Bronwyn Betts, Lord Ashcroft International Business School, Anglia Ruskin University, East Road, Cambridge, CB1 1PT, UK. E-mail: bronwyn.betts@anglia.ac.uk. 
paradigm and were used to explore the dynamics of the relationship between life history and attitude to learning. As suggested by Baker, West, and Stern (1992) cited in Wimping and Gass (2000), the researcher's own philosophy and beliefs will form the bedrock on which the choice of research method is based. Additionally it is imperative that the chosen method or methods are congruent with the research aims. In this study the author's own philosophical beliefs, the experiences of her students, the phenomenon under investigation, and the research aim all directed the methods used for data collection and analysis.

\section{The Chosen Methods}

\section{Life History}

The history method was chosen to gather data as it focuses on the ways individuals account for and theorise about their actions in the social world over time (Musson, 2004). In other words, it is basically retrospective. It focuses on the stories people tell about their lives so far. Goodson and Sikes (2001) suggest that it helps achieve a better understanding of the past in order to open up possibilities for the future and this was key in the decision to adopt the life history method for data collection. The in-depth interview was favoured as the tool for the collection for the data as it gave access to the respondents' accounts of how life history may have influenced their current attitude to learning. It was also chosen as it "fitted" with the epistemological standpoint adopted for the data analysis which was grounded theory (Glaser \& Strauss, 1967).

\section{Grounded Theory}

Although grounded theory is a method that can be used with any kind of data collection Glaser and Strauss (1967), Glaser (1978), and Charmaz (2007, p. 28) suggest that intensive qualitative interviewing fits grounded theory methods particularly well. Both grounded theory methods and intensive interviewing are open-ended yet directed, shaped yet emergent, and paced yet unrestricted.

Grounded theory is a general, inductive, and interpretive research method which was originated in 1967 by Glaser and Strauss (Glaser \& Strauss, 1967). Its method for analysing data was chosen, as already alluded to, because it fitted with the philosophical base of this research, that is to say the researcher did not set out to verify a theory, but to develop a theory which sought to explain how past experiences can influence attitude to learning. Grounded theory emphasises theory development. It focuses on unravelling the elements of experience then, as a result of studying these elements and their interrelationships a theory is developed which enables the researcher to understand the nature and meaning of an experience for a particular group of people in particular settings (Glaser \& Strauss, 1967).

\section{The Research Process}

Figure 1 provides an overview of the research process. Although the steps taken are presented in linear form, in reality these are often cyclical and interdependent processes.

All methodological decisions were perceived to meet key requirements for doctoral research, that is to say they fitted well with the research aims and philosophical underpinning. Identifying the substantive area to research (step 1) was relatively straightforward. Notwithstanding the interest which the student's reflections had generated, the researcher's own personal experiences had also contributed to the choice of direction that the research would take. Her own personal experiences of school were not positive and consequently it has always 
been a great puzzlement that throughout her adult life she had been motivated to engage in learning. This is all despite the fact that much of the literature suggests that people's willingness to engage in learning, particularly as adults, depends to considerable extent on whether they draw on positive experiences from this period of initial education and early years. Thus the study began with the identification of a substantive area which was of interest to the researcher, rather than a narrowly focussed research question (Corbin \& Strauss, 1998).

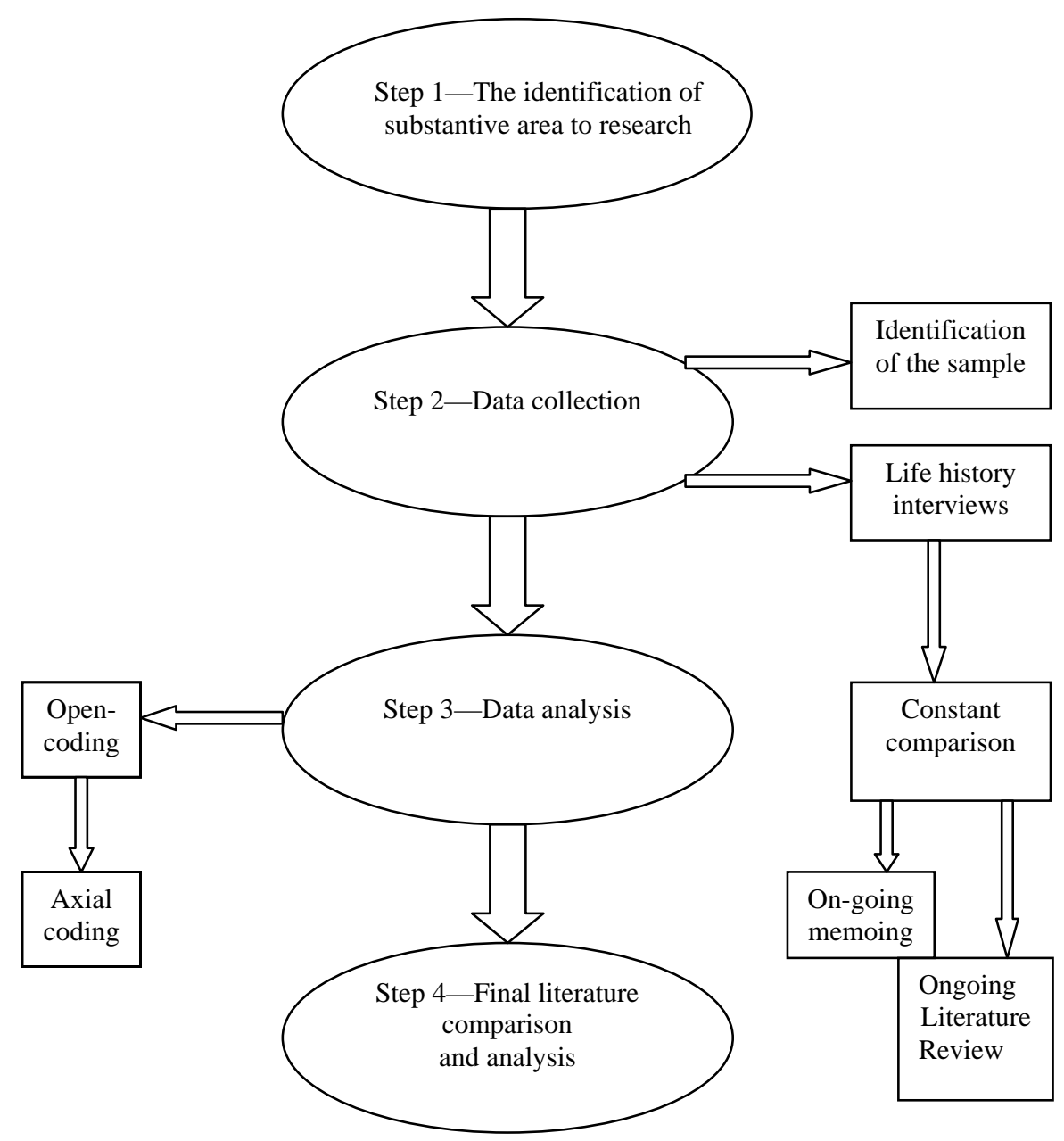

Figure 1. The research process.

\section{The Role of the Literature in Grounded Theory Research}

Whilst stage 1 did not cause too many problems step 2, data collection, was more problematic. When the literature should be consulted is a fundamental issue in grounded theory work. For Glaser and Strauss (1967), Glaser (1978), and Strauss (1987), the defining components of grounded theory practice include conducting the literature review after the collection and analysis of empirical data. This presented something of a dilemma, as on the one hand, the researcher was anxious to critique earlier studies to make comparisons with her findings from the interviews, on the other hand she did not want to import preconceived ideas and impose them on her work (Charmaz, 2007). 
In the end, the decision was influenced by two writers. Firstly, McGhee, Glenn, Marland, and Atkinson (2007), who suggests that the literature in grounded theory research is simply another source of data which should be theoretically sampled along with other emergent data. Theoretical sampling according to Charmaz (2007) is about: "Seeking pertinent data to develop your emerging theory. The main purpose of theoretical sampling is to elaborate and refine the Categories, constituting your theory” (p. 96).

The second influence was Onion (2004) who claims that the literature can be used as a form of primary as well as secondary data. Thus, as can be seen from Figure 1, a decision was made early in the research to delay the first real move into the literature until the process of open coding had taken place and then use it to theoretically sample.

\section{The Sample}

Grounded theory studies are characterised by theoretical sampling and this gave the study direction. However in order for this process to start there needs to be an initial sample for some data to be collected and analysed. Baker et al. (1992) maintain that the researcher using the grounded theory approach initiates the sampling process by interviewing significant individuals who have the knowledge and experience that the researcher requires, have the ability to reflect and articulate, and have the time. Thus, the sample chosen for the study was selected because the participants could provide relevant sources of data, they were relatively diverse in background but all shared a positive attitude to learning. Additionally, the size of the sample was quite small which reflected the view of Goodson and Sikes (2001) who purport that research samples for life history research are usually quite small. This relevance was determined by the requirements for generating and delimiting the theoretical codes (Hutchinson, 1993 as cited in Cutcliffe, 2003). Within this initial sample the researcher was concerned with generating as many categories as possible. Once these events or happenings had been categorised, she then sampled the literature with the aim to purposefully gather data related to these categories.

\section{Research Participants}

All respondents were either engaged in promoting learning and development within their organisation, or full-time students having recent past work experience and intending to re-join such organisations upon graduation. All students were interviewed in face-to-face informal interviews. The respondents were all interviewed in places convenient to them, either their places of work or at the college where they were attending their course.

Table 1 shows the gender, age, mode of study, and the type of employing organisations of the participants.

\section{The In-depth Interview}

As can be seen from Table 1 that the respondents were quite diverse in terms of age and background. The interviews began by the researcher asking the respondents to "offer a sequential account of their life" (Mann, 1992, p. 273), but more specifically throughout the narrative to focus on significant experiences of learning. The main aim was to elicit the respondent's subjective interpretation of the interaction between school, family work and learning within their lives. She was satisfied that most of the criteria for a good interview were met. Briggs (1986) suggests that good interviews are those in which the subjects are at ease and talk freely. 
Table 1

Gender and Age of Participants

\begin{tabular}{lc}
\hline Gender & Number \\
\hline Female & 18 \\
Male & 7 \\
Age range & Number \\
\hline $20-30$ & 10 \\
$30-40$ & 8 \\
$40-50$ & 7 \\
Mode of study & Number \\
\hline Full-time & 10 \\
Part-time & 15 \\
Employing organisation & Number \\
\hline Full-time students with recent past employment history & 10 \\
NHS & 3 \\
Private Training Organisation & 2 \\
Constabulary & 2 \\
Insurance Co. & 1 \\
Supermarket (a) & 1 \\
LEPRA & 1 \\
Supermarket (b) & 1 \\
Holiday Camp & 1 \\
Fashion Retailer & 1 \\
Construction Company & 1 \\
Learning Skills Council & 1 \\
\hline
\end{tabular}

Permission to tape the interviews was requested and given in all cases. Although transcripts of the interview where taken the researcher was keen to ensure that her body language communicated personal interest and attention.

Bogdan and Biklen (2002) advise that, when asking the respondent about the past, the interviewer suggests that he or she think back to that time and try to relive it. This proved to be a valuable strategy in the interviews when encouraging the respondents to contextualise their narrative, as did their reassurance that the interviewer need not fear silence. Silence can enable subjects to get their thoughts together. Another helpful lesson that was learnt was not to interrupt and change the direction of the narrative.

\section{Ethical Considerations}

Social science, like life, is shot through with personal, political, and ethical dilemmas (Plummer, 206, p. 277) and this research was no exception to this. The implication for informants in life history research was a particular concern. Goodson and Sikes (2001) suggest that it is not always possible to predict the sort of harm that informants may experience as a consequence of their involvements. An enormous amount of thought and attention was given in terms of what was going on in this regard and to the potential problems which may arise. The British Educational Research Association (BERA, 2004) considers that all education-related research should be conducted within an ethic of respect for the person. The participants in this research were active subjects and as the researcher was also their tutor she had a responsibility to them. She was aware that the life history approach to gathering data entailed reflecting on things that had happened in their lives, both good and bad. And she had a 
responsibility to avoid any embarrassment and intimidation, or to expose confidentialities (Stake, 2000).

It was emphasised that participation was voluntary and they would not be prejudiced if they refused to participate. They were assured of their right to withdraw their consent at any stage. The researcher was a senior member of staff in the college where the research was conducted at the time and, as their tutor she knew them reasonably well. This raised ethical issues about personal and professional responsibility. For in effect she was "doing research in her own back yard" (Goodson \& Sikes, 2001) with this in the forefront of her mind, she aimed to establish mutuality, minimise communication barriers, and allay discomfort (Seiber, 1993).

\section{Data Analysis Phase}

As already alluded to detailed transcripts were made following each interview and the data examined several times in order to develop explanations of the phenomenon being studied (Douglas, 2003, p. 46).

Memoing, or notes to self were made during and after the interviews. These were basically reflections on feelings of the relationship with the informant; any doubts about the quality of some the data, and any remark that related to a theory or concept which could be further explored in the literature (Strauss \& Corbin, 1998). Any issues were also noted which the researcher wanted to pursue further with the next contact or to re-interview at some point (Miles \& Huberman, 1994).

\section{Initial Coding}

The data in the transcripts and to some extent the memos was analysed phrase by phrase. This involved taking each phrase, examining and labelling. The labels were referred to as categories, concepts, and properties. This process of initial coding (or often referred to as open coding) requires application of what is referred to as the "comparative method" (Pandit, 1996) that is to say broken down and questions asked. For example, "What did this mean?”, "What is being referred to?”, “Who was involved?”, and "When did this happen?”. The data are then compared with data from the other interviews, grouped together and given a conceptual label. Table 2 is a worked example. The first two respondents mentioned the influence of family in the early years, so this was tentatively coded as "family influence". The categories helped make sense of what the participant had said. Whilst two participants mentioned the family influence, it was different depending on the context, characteristic, behaviour, and impact of the family. Properties were then examined, for example, the type of behaviour in the family, the extent of that behaviour and so on. The data from the coding were then used to theoretically sample the relevant literature in order to elaborate and refine the categories constituting a theory.

Table 2

Initial Coding

\begin{tabular}{|l|l|l|}
\hline Concept & Key categories & Properties \\
\hline \multirow{2}{*}{ Family influence } & Context & Frequency \\
& Characteristics & Extent \\
& Behaviour & Behaviour type \\
& Impact & Duration \\
\hline
\end{tabular}

\section{Axial Coding}

The next stage in the process of analysis is axial coding. This process allowed the researcher to examine the data more closely and identify relationships between the categories and properties identified in open coding. This 
is done in order to develop core or major codes. Axial coding utilises a coding paradigm which involves the researcher looking at the concepts, the context again and/intervening conditions involved. Consequences are then looked at in order to bring out the central idea or core category. So for example, after family influence had been analysed under the key categories and propertiesthe process of axial coding allowed her to think about the material in new ways and examine the data more closely under a different coding paradigm. This enabled her to build up a dense texture of relationships around the axes of the category being focussed upon. Hence Strauss and Corbin's (1998) definition of the process "axial coding”.

The emergent themes from axial coding as with the themes which emerged from the open coding procedure were then explored in greater detail against selected literature. This led to the identification of relationships between life experiences and attitudes to learning in later life.

\section{Findings}

The above process yielded a number of interesting findings and themes. The study presented evidence and supports previous findings that underline the important influence family and school have on developing a positive attitude to learning (Pugh, 1999; Pollard \& Bourne, 2002; Nutbrown \& Clough, 2006) and Pugh and Duffy (2007). It adds to the vast volume of literature in this area, in so far as whilst it may be the case that adults who are the best learners in terms of achievement come from homes value learning (Csikszentmihalyi, 1993), the findings suggest that adults who have had bad experiences of learning within the home and school can and do still go on to develop a positive attitude to learning in later life.

One respondent had a particularly negative experience at school and was told "she would never do anything with her life". She had remembered these words and they had, she claimed, made her more determined to succeed. She went on to obtain a 2:1 degree, a post graduate diploma and aspire to a very senior position in her organisation. Similar stories were told by many of the respondents. They were clearly driven by these negative experiences.

Another central theme which was drawn out is that individual perceptions of learning can be a key influence. The interviews bring out the differing perceptions and experiences of learning in schools and college as opposed to learning in the workplace. The research supported Pollard and Bourne's (2002) assertion that schools focus too much on curriculum and teaching whilst paying insufficient attention to social factors. The findings from my research support the viewpoint, which underlines the importance of making learning in schools more relevant and individualised.

Finally the influence and importance of context and learning was a recurring theme in the study. The respondents perceived the workplace environment as informal, supportive, and relevant in terms of meeting their learning needs. Unlike school and to a certain extent colleges, workplaces are developing the whole person, not just a single facet of the individual (Compton, Cox, \& Santon Laanan, 2006). The conclusions suggested that this research has shown the disjuncture between different phases of teaching (school, college, and the workplace).

\section{Some Final Thoughts}

The aim of this paper was to provide an insight into some of the issues of adopting grounded theory and life history methodologies. 
One of the biggest challenges of using grounded theory was adapting it to meet the researchers own needs. It takes a degree of confidence to take the general principles and practices of grounded theory and vary them according to individual research needs.

Grounded theory offers a set of guidelines rather than rigorous rules to be followed and as a novice researcher the researcher could have adopted a more structured practically orientated approach. However with grounded theory the data itself shapes the processes and product and for her it was important that she was not totally relying on pre-conceived ideas and had the flexibility to pursue emerging themes.

Life history as a methodology presented its own challenges. The researcher should never underestimate the importance of thoroughly familiarising themselves with this methodology and the associated ethical issues, some of which have been discussed within this paper. The implications for the respondents and the researcher role in particular require special consideration and attention. As reported earlier in this paper, it is not always possible to predict the sort of harm that informants may experience as a consequence of their involvement (Goodson \& Sikes, 2001).

Combining the two methodologies has not always been straightforward. However these two approaches provided valuable experience and insight into conducting phenomenological research. It can be summed up by Moustakas (1994):

In a phenomenological investigation the researcher has a personal interest in whatever she or he seeks to know, the researcher is intimately connected with the phenomenon, the puzzlement is autobiographical, making memory and history essential dimensions of discovery, in the present and extensions into the future. (p. 50)

\section{References}

Baker, C., West, J., \& Stern, P. (1992). Method slurring: The grounded theory/phenomenology example. Journal of Advanced Nursing, 17, 1355-1360.

BERA. (2004). Guidelines for ethical research. Retrieved from http://www.bera.ac.uk

Bogdan, R. C., \& Biklen, S. K. (1992). Qualitative research for education: An introduction to theory and methods (2nd ed.). Boston, M.A.: Allyn and Bacon.

Briggs, C. (1986). Learning how to ask: A sociolinguistic appraisal of the role of the interview in social science research. Cambridge, Massachusetts: Cambridge University Press.

Charmaz, K. (2007). Constructing grounded theory: A practical guide through qualitative analysis. London: Sage.

Compton, J. I., Cox, E., \& Santon Laanan, F. (2006). Adult learners in transition: New directions for student services. Retrieved from http://www.interscience.wiley.com/DO1.101002/ss.208

Corbin, J., \& Strauss, A. (1998). Basics of qualitative research: Techniques and procedures for developing grounded theory. London: Sage.

Csikszentmihalyi, I. (1993). Family influences on the development of giftedness. In G. R. Bock, \& K. Acknill (Eds.), The origins and development of high abilit. CIBA Foundation Symposium 178, Chichester, UK.

Cutliffe, R. (2003). Methodological issues in grounded theory. Journal of Advanced Nursing, 31(6), 176-194.

Douglas, D. (2003). Grounded theories of management: A methodological review. Management Research News, 26(5), 44-52.

Glaser, B. G. (1978). Theoretical sensitivity. Mill Valley, C.A.: Sociology Press.

Glaser, B., \& Strauss, A. (1967). Discovery of grounded theory. Chicago: Aldine.

Goodson, I., \& Sikes, P. (2001). Life history research in education settings: Learning from lives. Buckingham: Open University Press.

Mann, S. J. (1992). Telling a life story: Issues for research. Management Education and Development, 23(3), 271-280.

McGhee, G., Glenn, R., Marland, J., \& Atkinson, J. (2007). Grounded theory research: Literature reviewing and reflexivity. Journal of Advanced Nursing, 60(3), 334-342.

Miles, M. B., \& Huberman, A. M. (1994). Qualitative data analysis (2nd ed.). London: Sage. 
Moustakas, C. (1994). Phenomenological research methods. London: Thousand Oaks/Sage.

Musson, G. (2004). Life histories. In C. Cassell, \& G. Symon (Eds.), Essential guide to qualitative methods in organizational research (pp. 34-44). London: Sage.

Nutbrown, C., \& Clough, P. (2006). Inclusion in the early years: Critical analysis and enabling narratives. London: Sage.

Onion, P. (2004). Grounded theory applications. Reviewing Knowledge Management Literature, 1, 18.

Pandit, N. R. (1996). The creation of theory: A recent application of the grounded theory method. Retrieved from http://www.nova.edu/sss/QR/QR2-4/pandit.html

Plummer, K. (2006). Documents of life: An invitation to a critical humanism. London: Sage.

Pollard, A., \& Bourne, J. (2002). Teaching and learning in the primary school. London: Open University.

Pugh, G. (1999). Young children and their families: A community response. London: Falmer.

Pugh, G., \& Duffy, B. (2007). Contemporary issues in the early years. London: Sage.

Seiber, J. E. (1993). The ethics and politics of sensitive research. In C. M. Renzetti, \& R. M. Lee (Eds.), Researching sensitive topics (pp. 626-633). Newbury Park, C.A.: Sage.

Sikes, P., \& Gale, K. (2006). Narrative approaches to education research. Retrieved April 3, 2008, from http://www.edu.plymouth.ac.uk

Stake, P. (2000). Case studies. In N. K. Denscombe, \& Y. S. Lincoln (Eds.), Handbook of qualitative research (pp. 435-454), Thousand Oaks, C.A.: Sage.

Strauss, A. (1987). Qualitative analysis for social scientists. Cambridge: Cambridge University Press.

Strauss, A., \& Corbin, J. (1998). Basics of qualitative research: Grounded theory procedures and techniques (2nd ed.). London: Sage. 